\title{
COMISSÃO DE CULTURA E EXTENSÃO UNIVERSITÁRIA DA ESCOLA DE ENFERMAGEM DE RIBEIRÃO PRETO DA UNIVERSIDADE DE SÃO PAULO
}

\author{
Maria Lúcia Carmo Cruz Robazzi**

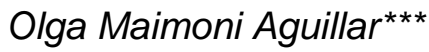

Fazendo um balanço das atividades desenvolvidas durante o ano de 1993, pela Comissão de cultura e Extensão Universitária (CCEx) da Escola de Enfermagem de Ribeirão Preto da Universidade de São Paulo, temos que, esta atendeu as diversas solicitações e necessidades de mostradas pela comunidade, gerenciando diversos cursos propostos por docentes dos três departamentos desta faculdade, cumprindo assim, com os objetivos relacionados a "Extensão Universitária".

Desta forma, na modalidade Difusão Cultural, 16 cursos foram ministrados, atendendo a 398 participantes, perfazendo o total aproximado de 390 horas. Esses cursos estão nominados abaixo:

- "Detecção precoce da Hipertensão Arterial: fatores de risco e medida indireta da pressão arterial", oferecido por três vezes durante o ano; "Diabetes Mellitus: considerações sobre a doença e cuidados básicos", "Princípios básicos de cicatrização e atendimento ao paciente na realização de curativos" e "Saúde do adulto com enfoque na prevenção das doenças", todos ministrados em dois períodos distintos, em 1993; "Esterilização e desinfecção: fundamentos e processos", "Atenção ao trabalho: primeiros socorros", "Procedimentos básicos de enfermagem", "Urgências e emergências", "Abordagem terapêutica do paciente psiquicamente perturbado nas urgências psiquiátricas", "Reabilitação de mastectomizada", "Operação com banco de dados em saúde", Editoração gráfica de textos", "Redação técnica", "Tópicos fundamentais de infecção hospitalar" e "Aspectos fundamentais sobre a AIDS", todos esses ministrados uma vez, durante o referido ano.

Na modalidade Atualização, foram oferecidos 12 cursos, perfazendo o total de 548 horas,

\footnotetext{
**Presidente da Comissão de Cultura e Extensão Universitária e Professora Doutora do Departamento de Enfermagem Geral e Especializada da Escola de Enfermagem de Ribeirão Preto da Universidade de São Paulo.

***Vice-Presidente da Comissão de Cultura e Extensão Universitária e Professora Doutora do Departamento de Enfermagem Geral e Especializada da Escola de Enfermagem de Ribeirão Preto da Universidade de São Paulo.
} 
atendendo a 290 participantes, cursos esses designados a seguir:

- "Saúde do adulto: promoção da saúde e prevenção das doenças crônicas", ministrado em três períodos distintos, "Ações básicas na assistência à saúde da criança" e "Procedimentos básicos de enfermagem", oferecido por duas vezes; "Assistência ao paciente ostomizado: aspectos atuais", "Uma nova perspectiva do atendimento ambulatorial em nutrição", "Assistência integral ao trinômio: mãe, pai e filho no processo de aleitamento materno", "Assistência integral à mulher no processo de aleitamento materno", "Projeto aleitamento materno nas Unidades Básicas de Saúde de Ribeirão Preto", "Introdução à microinformática", "Auto cuidado com a mama puerperal" e "Aplicação de injetáveis", todos esses ministrados por uma vez, durante 1993.

A Comissão de Cultura e Extensão Universitária também promoveu a organização dos eventos comemorativos, dos 40 anos da Escola de Enfermagem de Ribeirão Preto da Universidade de São Paulo, realizando diversas atividades, tais como: publicações sobre o assunto em jornais locais, lançamento de "botton" comemorativo, realização de uma Retrospectiva Histórica da Escola, realização de uma exposição fotográfica, lançamento de um vídeo ou ainda parte do "staff" da instituição. Dentre essas atividades, grande significância teve o Encontro Nacional "Perspectivas e Prospectivas em Enfermagem", realizado no período de 11 a 13 de agosto. Esse encontro reuniu profissionais e alunos de graduação em enfermagem, que discutiram durante esses dias os vários aspectos relacionados ao ensino de graduação, a pesquisa e aos serviços de extensão à comunidade. Receberam premiações os dois melhores trabalhos científicos de alunos de graduação, bem como os dois melhores trabalhos de pesquisa, realizados por profissionais.

Em relação aos projetos originalmente propostos pela Pró-Reitoria de Cultura e Extensão Universitária da Universidade de São Paulo, a Comissão de Cultura e Extensão Universitária gerenciou e/ou coordenou a nível local, na Escola de Enfermagem de Ribeirão Preto os que se seguem:

- "Universidade e as Profissões", realizado em 09 de agosto, quando a Unidade foi visitada por 300 alunos, das várias escolas de $2^{\circ}$ grau de Ribeirão Preto e região, estudantes esses que estão na fase de escolha de sua carreira profissional;

- "Universidade Aberta à Terceira Idade", projeto no qual disciplinas ministradas no Curso de Graduação em Enfermagem são abertas a pessoas idosas da comunidade. Assim, esteve aberta à comunidade a disciplina "Enfermagem Gerontológica e Geriátrica"; o grupo denominado "Grupo de vivência dos idosos aposentados" que se reúne semanalmente e é constituído, por cerca de 25 idosos; e onde palestras foram ministradas aos idosos, dentre as quais: "O processo de envelhecer", "Debate Mellitus e o Idoso", "Fatores de risco da Hipertensão Arterial" e "A fome no idoso". 
A partir do mês de outubro, a CCEx de Escola de Enfermagem de Ribeirão Preto coordenou reuniões entre os enfermeiros representantes do Sistema Único de Saúde (SUS) a nível estadual e municipal, com docentes desta Escola. Nesta ocasião, solicitações foram feias pelos enfermeiros quanto a realização de cursos para a rede básica de saúde o que professores se propuserem a atender, fortalecendo dessa forma o convênio já existente entre o Sistema Único de Saúde e a Escola de Enfermagem de Ribeirão Preto da Universidade de São Paulo. Em atendimento às solicitações feitas, 14 cursos extracurriculares foram aprovados pela CCEx para 1994, incluindo-se nestes o curso de Especialização em Saúde Pública. A relação de cursos será divulgada posteriormente.

A nível internacional, a CCEx tem assessorado a direção da unidade nas atividades pertinentes ao Centro Colaborador para o Desenvolvimento da Pesquisa em Enfermagem OPS/OMS. Dessa forma, essa comissão realiza o gerenciamento do Centro, o que resulta em importantes atividades de caráter internacional.

Dentre as atividades, temos a responsabilidade pela divulgação dos principais eventos na área de enfermagem e da saúde, que são repassados ao Brasil e a América Latina através do Informativo Latino-Americano de Enfermagem. Da mesma forma, as informações contidas no Global Network News, publicação editada em inglês e que contempla as notícias dos diversos Centros Colaboradores em Enfermagem da Organização Mundial da Saúde, são divulgadas neste Informativo.

Programações foram feitas para recepção de profissionais brasileiros e internacionais, procurando atender aos objetivos previstos para cada uma das visitas. Temos como exemplo, algumas dessas visitas:

- do assessor do Ministério da Saúde do governo de Moçambique, Dr. Herculano Bata, que esteve em Ribeirão Preto em abril e visitou a Escola de Enfermagem de Ribeirão Preto da Universidade de São Paulo, interessado em conhecer os Cursos de Graduação e PósGraduação aqui oferecidos, citando a possibilidade de um possível convênio no futuro, a ser realizado entre o Ministério e essa Unidade da Universidade de São Paulo:

- da delegação angolana, composta por quatro membros, que permaneceu durante três dias, em junho, a fim de serem revistos alguns aspectos relativos ao convênio entre a Universidade de São Paulo e a República de Angola;

- da Professora Jasna Stiepovich Bertoni, da Universidad de Concepción, situada em Concepción no Chile, em novembro, cujo objetivo foi tratar da elaboração de um Termo de Acordo Mútuo do Programa de Doutoramento em Enfermagem, entre a Escola de Enfermagem de Ribeirão Preto da Universidade de São Paulo e o Departamento de Enfermería de la Faculdad de Medicina de la Universidad de Concepción.

Em relação às atividades culturais, a Comissão de Cultura e Extensão Universitária tradicionalmente promoveu, as festividades comemorativas da Páscoa, do mês de junho (Festas 
Juninas), da Primavera e do Natal. Apoiou também as iniciativas de apresentação na Unidade de grupos de música, teatro, exposições fotográficas e de pinturas, entre outras.

Essa Comissão têm auscutado docentes e funcionários da Unidade, no sentido de atender as suas expectativas, no que diz respeito às atividades culturais e de extensão.

Dessa forma, temos trabalhado, no sentido de estarmos atendendo aos objetivos propostos para esta comissão. 